\title{
PROTECTIVE EFFECT OF L-CARNITINE AGAINST CISPLATIN- INDUCED TESTICULAR TOXICITY IN RATS
}

\author{
BY \\ Ahmed H. Eid ${ }^{a}$, Noha F. Abdelkader ${ }^{\mathrm{b}}$, Ola M. Abd El-Raouf ${ }^{\mathrm{a}}$, Hala M. Fawzy ${ }^{\mathrm{a}}$, Bahia M. El- \\ Sayeh $^{\mathrm{b}}$, Ezz-El-Din S. El-Denshary ${ }^{\mathrm{b}}$ \\ FROM \\ a Department of Pharmacology, National Organization for Drug Control and Research \\ (NODCAR), Giza, Egypt \\ ${ }^{b}$ Department of Pharmacology and Toxicology, Faculty of Pharmacy, Cairo University, Cairo, \\ Egypt.
}

\begin{abstract}
Testicular damage is one of the most deleterious effects whenever cisplatin (CIS) is employed in cancer chemotherapy. Oxidative stress has been proven to be involved in CIS induced toxicity. Thus, the current study explored the possible protective effect of L-carnitine (L-CAR) against cisplatin-induced testicular damage in rats. L-carnitine $(500 \mathrm{mg} / \mathrm{kg} / \mathrm{day}$; i.p.) was injected for 15 days, whereas cisplatin $(10 \mathrm{mg} / \mathrm{kg}$; i.p.) was injected as a single dose at the $12^{\text {th }}$ day to induce testicular damage in adult male Sprague-Dawley rats. In the current study, CIS reduced the reproductive organs weight, sperm count, sperm motility and serum testosterone level beside a marked increase in the incidence of sperm abnormalities. In addition, it significantly increased malondialdehyde (MDA) and nitric oxide (NO) along with a marked decrease in testis reduced glutathione (GSH) content and superoxide dismutase (SOD), catalase (CAT) and glutathione peroxidase (GPx) activities. At the same time, CIS administration resulted in marked elevation in tumor necrosis factor- $\alpha$ (TNF- $\alpha$ ) production and nuclear factorkabba B (NF- $\mathrm{KB})$ expression. These results were confirmed by histopathological examination. Treatment with L-CAR markedly attenuated cisplatin-induced injury by suppression of oxidative/nitrosative stress and inflammation, amendment of antioxidant defenses, as well as improvement of steroidogenesis, spermatogenesis and testicular histological features. This study suggests a novel therapeutic application for L-carnitine as a protective agent against cisplatininduced testicular toxicity through its promising anti-inflammatory and antioxidant capacities.
\end{abstract}

Key words: Cisplatin; L-carnitine; Inflammation; Oxidative stress; Testicular damage.

\section{Introduction}

Cisplatin is a highly effective and commonly used DNA alkylating chemotherapeutic agent for the treatment of diverse types of solid tumors (Amin and Buratovich, 2009). Despite the improvement in quality of life of cancer patients; the use of cisplatin was restricted clinically by its major side effects including testicular toxicity (Fung and Vaughn, 2011; Beytur et al., 2012). In adult men, fertility can be preserved by spermatozoa cryopreservation and intracytoplasmic sperm injection; however, these methods are not feasible options for prepubertal patients (Rezvanfar et al., 2013). Besides, in adults, the freezing and thawing of semen can reduce the sperm quality (Maines et al., 1990).

Cisplatin was found to produce severe testicular toxicity, characterized by impaired spermatogenesis, sperm DNA damage and sperm chromosomal abnormalities (Fung and 
Vaughn, 2011; Beytur et al., 2012). The mechanisms underlying cisplatin-induced testicular injury involves disruptions of the redox balance of testicular tissues via an increase in mitochondrial dysfunction, oxidative/nitrosative stress and lipid peroxidation which result in inhibition of protein synthesis and DNA damage (Ahmed et al., 2011; Rezvanfar et al., 2013). Interestingly, growing evidences revealed that combination therapy of cisplatin with antioxidants can be beneficial to overcome this special reproductive toxicity (Ahmed et al., 2011; Turk et al., 2011; Aldemir et al., 2014; Sherif et al., 2014).

L-carnitine, is a natural amino acid with a major role in cellular energy production and has been considered a promising cytoprotective agent (Sayed-Ahmed, 2010; Radwan et al., 2012). It is essential for the $\beta$-oxidation of fatty acids in mitochondria to generate ATP (AlMajed, 2007; Aleisa et al., 2007). L-carnitine was found to possess strong antioxidant, antiinflammatory and antiapoptotic properties (Izgut-Uysal et al., 2003; Cetinkaya et al., 2006; Dokmeci et al., 2007).

L-carnitine has also been shown to play an important role in the control of the male reproductive system and normal function of the testis, where it is highly concentrated in the male reproductive system, especially in the epididymis ( $\mathbf{N g}$ et al., 2004). It acts on male gamete maturation and seems to have a key role in: providing readily available energy for sperm motility (Ruiz-Pesini et al., 2001; Ng et al., 2004), sperm DNA repair (Garcia et al., 2006), germ cell recovery (Topcu-Tarladacalisir et al., 2009), protecting sperms against oxidative damage, reducing apoptosis of spermatogenic cells and inhibiting sperms aggregation (Abdelrazik and Agrawal, 2009).

Nutritional supplementation with L-carnitine improves sperm quality and/or quantity in the testis of rat (Kanter et al., 2010) and mice (Ahmed et al., 2014) exposed to X-ray irradiation. Furthermore, it has been shown that L-carnitine has protective effects on the testis of atherosclerotic rats (Salama et al., 2015). In addition, L-carnitine has a protective effect on di (2-ethylhexyl) Phthalate (Zare et al., 2011), ischaemia-reperfusion (Dokmeci et al., 2007) and etoposide (Okada et al., 2009) induced testis injury in rats.

In view of these considerations, the functional health effect of L-carnitine in protecting against cisplatin toxicity could be of current interest. Therefore, the aim of this study was to evaluate the potential protective effects of L-carnitine against testicular toxicity induced by cisplatin in male rats by the assessment of hormonal and spermatological changes, oxidative stress parameters, inflammatory markers, and the testicular histopathological alterations.

\section{Material and methods}

\subsection{Drugs and Chemicals}

Cisplatin (10mg/10ml) was purchased from Mylan, Saint-Priest, France. L-carnitine was purchased from Arab company for pharmaceutical and medicinal plant (MEPACO), Cairo, Egypt. All other chemicals were of the highest purity and analytical grade.

\subsection{Animals}


Male adult Sprague-Dawley rats 250-280 g, were obtained from the breeding colony of the National Organization for Drug Control and Research (NODCAR), Giza, Egypt. Animals were accommodated under controlled environmental conditions $\left(23 \pm 2^{\circ} \mathrm{C}\right.$ temperature, $60 \pm 10 \%$ humidity, 12/12 h light/dark cycle) and were allowed standard chow diet and water ad libitum. The investigation complies with the Guide for the Care and Use of Laboratory Animals (NIH Publication No. 85-23, revised 1996) and was approved by the Ethics Committee of Faculty of Pharmacy, Cairo University, Cairo, Egypt (Permit Number: PT 922).

\subsection{Experimental design and protocol}

Forty male rats were randomly divided into four groups ( $\mathrm{n}=10$ rats per each). Group I: animals were fed with normal diet for 15 days (Control). Group II: animals were treated with Lcarnitine (500 mg/kg/day; i.p.) for 15 days (Cayir et al., 2009). Group III: animals were fed with normal diet for 15 days and received a single intraperitoneal dose of cisplatin $(10 \mathrm{mg} / \mathrm{kg})$ on $12^{\text {th }}$ day (Longo et al., 2011). Group IV: animals were treated with L-carnitine $(500 \mathrm{mg} / \mathrm{kg} /$ day; i.p.) for 15 days as well as a single intraperitoneal dose of cisplatin $(10 \mathrm{mg} / \mathrm{kg})$ on $12^{\text {th }}$ day. Animals were weighed and scarified by decapitation 24 hours after the last treatment for collection of serum and for examination of the semen parameter. Testis and other reproductive accessory organs were immediately removed and cleaned from the adhering tissue and weighed.

\subsection{Analysis of blood samples}

Blood samples were collected from the retro-orbital sinus (Cocchetto and Bjornsson, 1983) of each rat, and the sera were separated and kept at $-80^{\circ} \mathrm{C}$ till determination of testosterone level. Serum level of testosterone was assayed using Rat Testosterone EIA kit (Enzo life sciences, San Diego, USA) according to the manufacturer procedure.

\subsection{Analysis of tissue samples}

The testis were removed and cleaned from the adhering tissue and weighed. The right testis was decapsulated and homogenized in ice-cold $0.05 \mathrm{M}$ potassium phosphate buffer $(\mathrm{pH}$ 7.4) to give $10 \%$ homogenate and samples were stored at $-80^{\circ} \mathrm{C}$ till estimations of the biochemical parameters. The left testis was preserved in $10 \%$ formalin for histopathological and immunohistochemical examination.

\subsubsection{Determination of testicular oxidative stress biomarkers}

Malondialdahyde (MDA), as an index for lipid peroxidation, was determined in testicular homogenate by detecting the absorbance of thiobarbituric acid reactive substances at $535 \mathrm{~nm}$ (Erdincler et al., 1997). Another aliquot of the testicular homogenate was mixed with $5 \%$ sulfosalicylic acid and centrifuged at $1000 \mathrm{x}$ g for $15 \mathrm{~min}$. The resulting protein-free supernatant was used for the determination of reduced glutathione (GSH) according to the method described by Beutler et al. (1963). The third proportion of the testicular homogenate was centrifuged at $4000 \mathrm{rpm}$ for 15 minutes at $4{ }^{\circ} \mathrm{C}$ and the clear supernatant was used for determination of the testicular superoxide dismutase (SOD), catalase (CAT), glutathione peroxidase (GPX) activities and nitric oxide (NO) content using the Biodiagnostic Colorimetric Kits (Cairo, Egypt) according to the manufacturer's instruction.

\subsubsection{Determination of testicular tumor necrosis factor-alpha (TNF- $\alpha)$ content}


Testicular homogenate was centrifuged at $4000 \mathrm{rpm}$ for 15 minutes at $4{ }^{\circ} \mathrm{C}$ and the resulting supernatant was used for the determination of TNF- $\alpha$ using Rat TNF- $\alpha$ Elisa reagent kit (Enzo life sciences, San Diego, USA) according to the manufacturer procedure.

\subsubsection{Evaluation of the sperm parameters}

The epididimal content of each rat was obtained after cutting the tail of epididymis and squeezing it gently in sterile clean watch glass and examined according to the technique adopted by Bearden and fluquary (1980) for the estimation of sperm count, motility and abnormalities.

\subsubsection{Histological study}

The fixed testis was processed for paraffin embedding and $4 \mu \mathrm{m}$ sections were prepared. Testicular sections were stained with haematoxylin and eosin (H\&E) and examined using a light microscope (40x). Qualitative histopathological damage in the seminiferous tubules was graded according to the severity of degenerative findings: $(-)$ no obvious damage, $(+)$ fewer than $25 \%$ of seminiferous tubules affected (mild), (++) 25-50\% of seminiferous tubules affected (moderate), and (+++) over $50 \%$ of seminiferous tubules affected (severe) (Rezvanfar et al., 2013). Histopathological examination of testes was interpreted by an experienced observer who was blind to the sample identity to avoid any bias.

\subsubsection{Testicular NF-אB immunohistochemical examination}

Paraffinized testicular sections from control and the various treated groups were deparaffinized in xylene, dehydrated in graded alcohol, and finally hydrated in water. Antigen unmasking was performed by incubating the sections for $20 \mathrm{~min}$ in citrate buffer (Thermo Fisher Scientific, Fremont, $\mathrm{CA} ; \mathrm{pH}$ 6.0) at the boiling point then cooled. Sections were then incubated overnight at $4^{\circ} \mathrm{C}$ with the rabbit polyclonal anti-NF- $\kappa \mathrm{B}$ primary antibody $(1: 200$; Invitrogen, Carlsbad, CA). After washing with phosphate-buffered saline (PBS), the slides were incubated for 30 min at $37^{\circ} \mathrm{C}$ with the biotinylated secondary antibody then with the Vector Elite ABC kit (Avidin DH and biotinylated horseradish peroxidase $\mathrm{H}$ reagents; Vector Laboratories Inc., Burlingame, CA). After another wash with PBS, the antibody-biotin-avidin-peroxidase complex was developed using diaminobenzidine tetrahydrochloride (DAB Substrate Kit, Vector Laboratories Inc.). Sections were counterstained with hematoxylin, dehydrated, and cleared in xylene then cover slipped and examined through the light microscope (400x), where the reaction appeared as a brown cytoplasmic reaction.

\subsection{Statistical analysis}

Data were expressed as means \pm standard error of the mean (SE). The statistical significance between the means of different groups was analyzed using one way analysis of variance (ANOVA) followed by Tukey-Kramer multiple comparison test. Level of statistical significance was set at $p<0.05$. Prism computer program (GraphPad software Inc. V5, San Diego, CA, USA) was used to carry out all statistical tests.

\section{Results}

There was no change in any of the tested parameters between the control rats and those which received L-carnitine (at the selected dose).

\subsection{Effects on reproductive organs weights}


Cisplatin administration resulted in a significant decrease in body as well as relative reproductive organs weight when compared to control group. Cisplatin decreased body weight to $87.7 \%$ of control rats, an effect that was not alleviated by L-carnitine treatment. The relative weights of right and left testis, cauda epididymis, prostate and seminal vesicle were significantly decreased after cisplatin exposure to $82.9 \%, 85.2 \%, 76.6 \%, 73.7 \%$ and $80.7 \%$ of the control group; respectively, while all of them were normalized by L-carnitine administration (Table 1).

Table 1. Effects of L-carnitine on cisplatin-induced alterations in body and reproductive organs weight in rats.

\begin{tabular}{|c|c|c|c|c|c|c|}
\hline Groups & $\begin{array}{l}\text { Final body } \\
\text { weight (g) }\end{array}$ & $\begin{array}{c}\text { Right testes } \\
(\mathrm{g} \cdot(100 \mathrm{~g} \\
\left.\text { BW })^{-1}\right)\end{array}$ & $\begin{array}{c}\text { Left testes } \\
(\text { g. }(100 \mathrm{~g} \\
\left.\text { BW })^{-1}\right)\end{array}$ & $\begin{array}{l}\text { Cauda } \\
\text { epididymis } \\
(\mathrm{g} \cdot(100 \mathrm{~g} \\
\text { BW-1) }\end{array}$ & $\begin{array}{l}\text { Prostate } \\
(\mathrm{g} .(100 \mathrm{~g} \\
\left.\text { BW })^{-1}\right)\end{array}$ & $\begin{array}{c}\text { Seminal } \\
\text { vesicles } \\
(\text { g. }(100 g \\
\left.\text { BW })^{-1}\right)\end{array}$ \\
\hline Control & $283.0 \pm 3.86$ & $0.498 \pm 0.005$ & $\begin{array}{c}0.493 \pm \\
0.005\end{array}$ & $0.047 \pm 0.002$ & $0.217 \pm 0.003$ & $0.265 \pm 0.004$ \\
\hline L-CAR & $\begin{array}{c}283.4 \pm \\
3.31\end{array}$ & $\begin{array}{c}0.505 \pm \\
0.005\end{array}$ & $\begin{array}{c}0.507 \pm \\
0.004\end{array}$ & $\begin{array}{c}0.051 \pm \\
0.001\end{array}$ & $\begin{array}{c}0.246 \pm \\
0.004^{*}\end{array}$ & $\begin{array}{c}0.285 \pm \\
0.004\end{array}$ \\
\hline CIS & $248.3 \pm 2.77^{*}$ & $0.413 \pm 0.010^{*}$ & $\begin{array}{c}0.420 \pm \\
0.011^{*}\end{array}$ & $0.036 \pm 0.002^{*}$ & $0.160 \pm 0.006^{*}$ & $0.214 \pm 0.007^{*}$ \\
\hline $\begin{array}{l}\text { CIS + } \\
\text { L-CAR }\end{array}$ & $251.6 \pm 3.6$ & $\begin{array}{l}0.512 \pm \\
0.011\end{array}$ & $\begin{array}{l}0.508 \pm \\
0.012\end{array}$ @ & $0.047 \pm$ & $\begin{array}{l}0.214 \pm \\
0.008\end{array}$ @ & $\begin{array}{l}0.259 \pm \\
0.013^{\circledR}\end{array}$ \\
\hline
\end{tabular}

Note: Values are expressed as mean \pm SEM of 10 animals in each group. *vs control, @ vs CIS (one-way ANOVA followed by Tukey-Kramer multiple comparisons test; $\mathrm{p}<0.05$ ). CIS, cisplatin; L-CAR, L-carnitine; BW, body weight.

\subsection{Effects on sperm parameters and serum testosterone level}

Table 2 showed a substantial decrease in sperm count and motility $\%$ almost by half and an increase in sperm abnormalities $\%$ to 2.7 folds with cisplatin administration compared to the corresponding values of the control group. Furthermore, serum testosterone level was markedly declined to $73.3 \%$ of the control group. Treatment with L-carnitine completely alleviated the changes induced by cisplatin with restoration of the normal values of all sperm parameters and serum testosterone level.

Table 2. Effects of L-carnitine on cisplatin-induced alterations in spermatological parameters and serum testosterone level in rats.

\begin{tabular}{lcccc}
\hline Groups & $\begin{array}{c}\text { Sperm count } \\
\left(\mathbf{1 0}^{\mathbf{7}} \cdot \mathbf{m l}^{\mathbf{- 1}}\right)\end{array}$ & $\begin{array}{c}\text { Sperm motility } \\
(\boldsymbol{\%})\end{array}$ & $\begin{array}{c}\text { Sperm } \\
\text { abnormalities } \\
(\boldsymbol{\%})\end{array}$ & $\begin{array}{c}\text { Testosterone } \\
\left(\mathbf{p g . m l} \mathbf{~}^{\mathbf{1}}\right)\end{array}$ \\
\hline Control & $167.0 \pm 5.60$ & $81.88 \pm 1.61$ & $5.28 \pm 0.14$ & $5605 \pm 98.7$ \\
\hline
\end{tabular}




\begin{tabular}{lcccc}
\hline L-CAR & $168.9 \pm 4.08$ & $82.5 \pm 1.63$ & $5.24 \pm 0.30$ & $5416 \pm 65.60$ \\
CIS & $91.38 \pm 4.76^{*}$ & $53.75 \pm 3.62^{*}$ & $14.29 \pm 0.67^{*}$ & $4107 \pm 243.4^{*}$ \\
CIS+L-CAR & $160.8 \pm 4.40^{\Theta}$ & $74.38 \pm 2.20^{\Theta}$ & $7.33 \pm 0.46^{\Theta}$ & $5197 \pm 128.6^{\Theta}$ \\
\hline
\end{tabular}

Note: Values are expressed as mean \pm SEM of 10 animals in each group. ${ }^{*}$ vs control, ${ }^{\circledR}$ vs CIS (one-way ANOVA followed by Tukey-Kramer multiple comparisons test; $\mathrm{p}<0.05$ ). CIS, cisplatin; L-CAR, L-carnitine; BW, body weight.

\subsection{Effects on the testicular TNF- $\alpha$ and the oxidative stress biomarkers levels}

Cisplatin injection markedly amplified testicular MDA, NO, and TNF- $\alpha$ contents by 3.6 , 1.6 and 5.2 folds, respectively; whereas it resulted in a decline in testicular GSH content along with SOD, CAT and GPx activities by $60.47 \%, 56.41 \%, 47.10 \%$ and $65.90 \%$, respectively as compared to the control group. L-carnitine resulted in a significant increase in SOD activity and GSH content to $191 \%$ and $166 \%$, respectively; when compared to cisplatin treated group, and caused restoration of the normal values of MDA, NO, TNF- $\alpha$, CAT and GPx (Fig. 1-3).
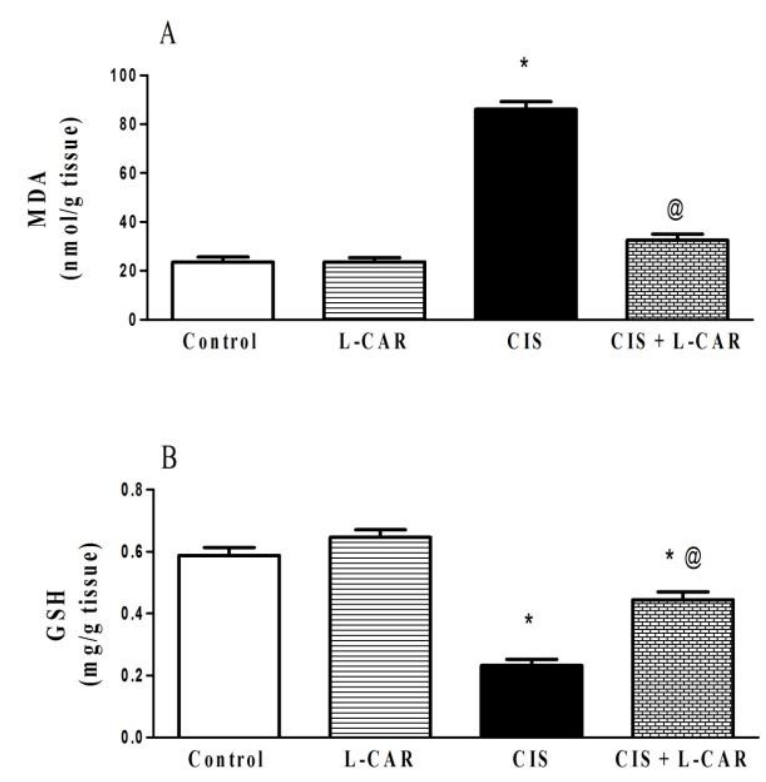

Fig. 1. Effect of L-carnitine on cisplatin-induced alterations in testicular MDA and GSH levels in rats. Each bar represents the mean \pm SEM of 10 animals in each group; ${ }^{*}$ vs control, ${ }^{@}$ vs CIS (one-way ANOVA followed by Tukey-Kramer multiple comparisons test; $\mathrm{p}<0.05$ ). CIS, cisplatin; L-CAR, L-carnitine. 

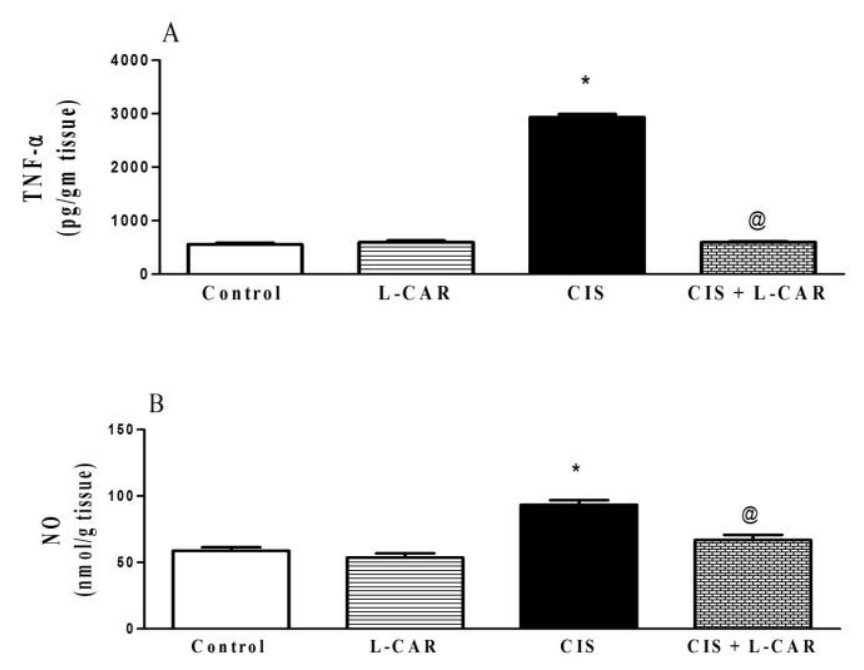

Fig. 2. Effect of L-carnitine on cisplatin-induced alterations in testicular TNF- $\alpha$ and NO levels in rats. Each bar represents the mean \pm SEM of 10 animals in each group; ${ }^{*}$ vs control, ${ }^{\circledR}$ vs CIS (one-way ANOVA followed by Tukey-Kramer multiple comparisons test; $\mathrm{p}<0.05$ ). CIS, cisplatin; L-CAR, L-carnitine.
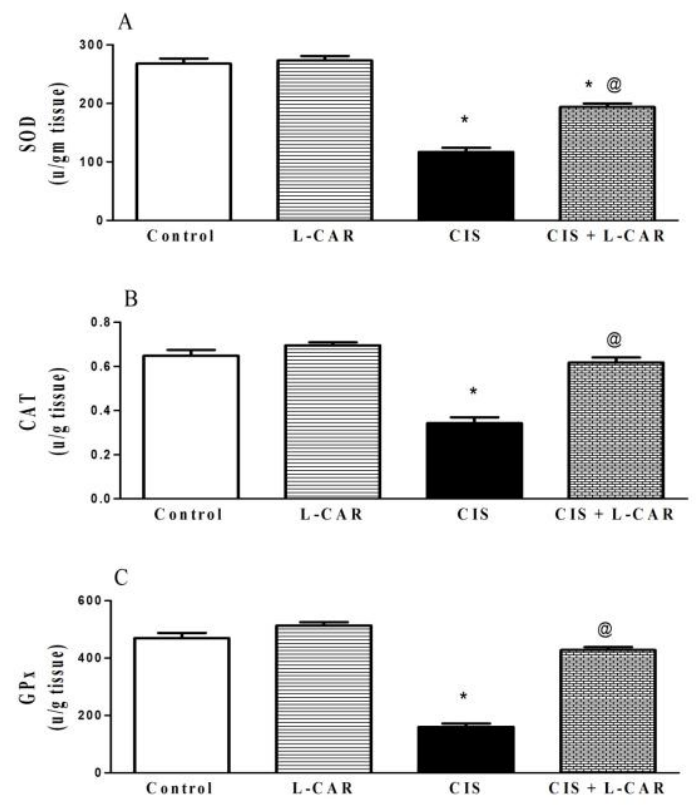

Fig. 3. Effect of L-carnitine on cisplatin-induced alterations in testicular SOD, CAT and GPx activities in rats. Each bar represents the mean \pm SEM of 10 animals in each group; ${ }^{*}$ vs control, ${ }^{\circledR}$ vs CIS (one-way ANOVA followed by Tukey-Kramer multiple comparisons test; $\mathrm{p}<0.05)$. CIS, cisplatin; L-CAR, L-carnitine.

\subsection{Effects on testicular $N F-\kappa B$ expression}

Sections in testis of cisplatin treated rats displayed an enhanced NF- $\mathrm{BB}$ protein expression confined within the interstitial stroma adjacent to the basement membrane of 
degenerated tubules (Fig. 4C \& Table 3), an effect that alleviated by management with Lcarnitine (Fig. 4D \& Table 3).

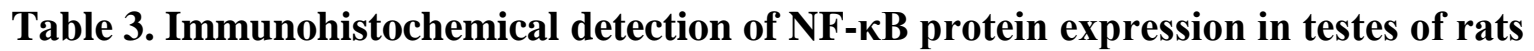

Groups

Control

L-CAR

CIS

CIS+L-CAR
NF-кB expression

(in the interstitial stroma)

Note: - Nil, + mild, ++ moderate, +++ extensive, ++++ very extensive. CIS, cisplatin; L-CAR, L-carnitine.
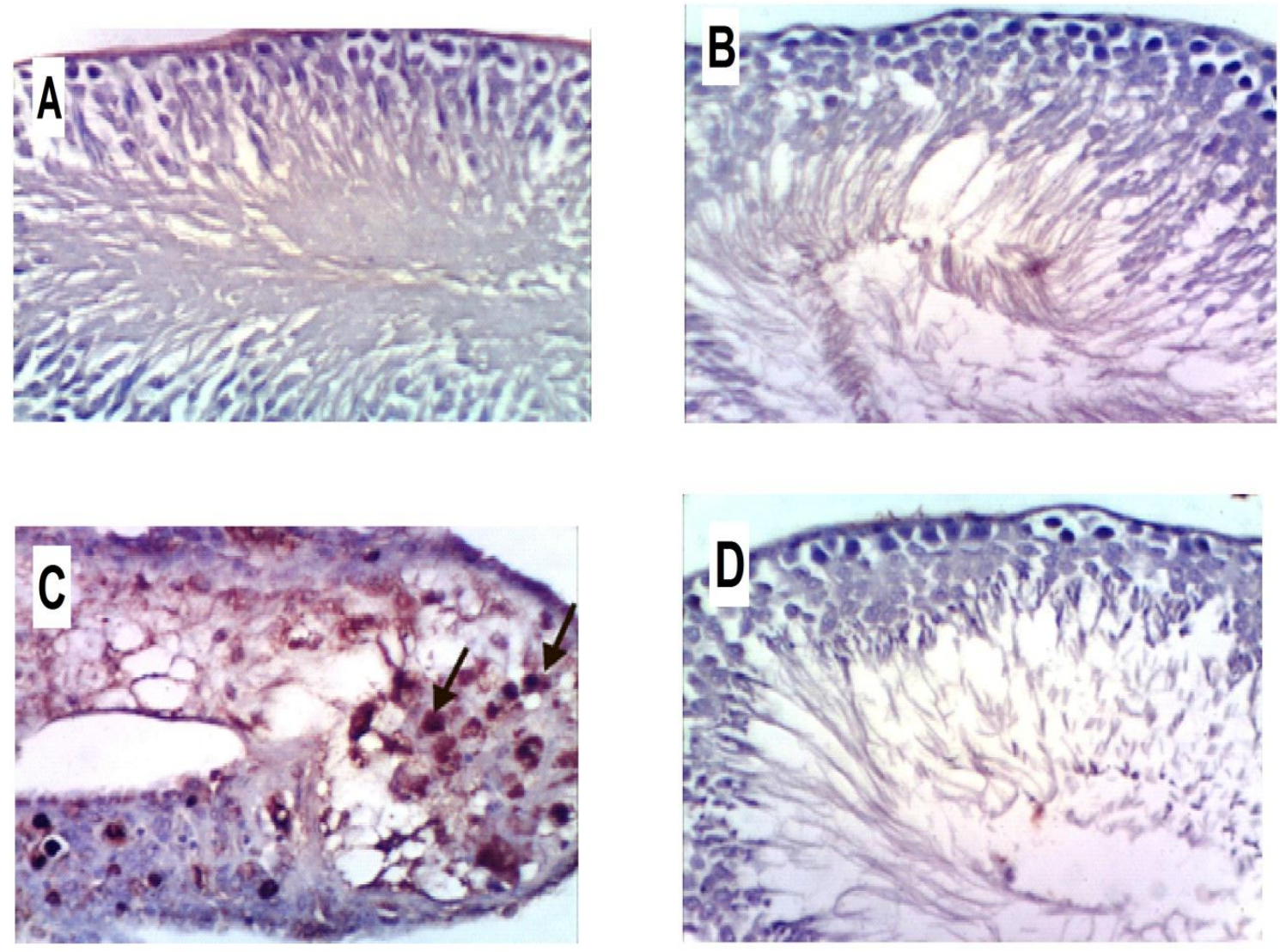

Fig. 4. Effect of L-carnitine on cisplatin-induced alterations in testicular NF- $\mathrm{B}$ protein expression in rats. Photomicrographs illustrating immunohistochemical staining of NF- $\kappa B$ in testicular sections; (A) control and (B) L-CAR groups showing negative expression, (C) CIS 
treated group showing very extensive expression (arrows), (D) CIS+L-CAR displaying negative expression [Magnification: X 400]. CIS, cisplatin; L-CAR, L-carnitine.

\subsection{Effects on hematoxylin and eosin sections}

Testicular sections of the cisplatin group revealed atypical morphological features manifested as massive degeneration in the seminiferous tubules, shrinkage in germ cell layers and disruption of spermatogenesis, interstitial edema, congestion in blood vessels and replacement of the interstitial stroma with homogeneous eosinophilic material (Fig. 5C \& Table 4). L-carnitine treatment normalized these histological abnormalities and amended spermatogenesis, though a slight some homogenous eosinophilic material in the interstitial stroma (t) was still observed (Fig. 5D \& Table 4).
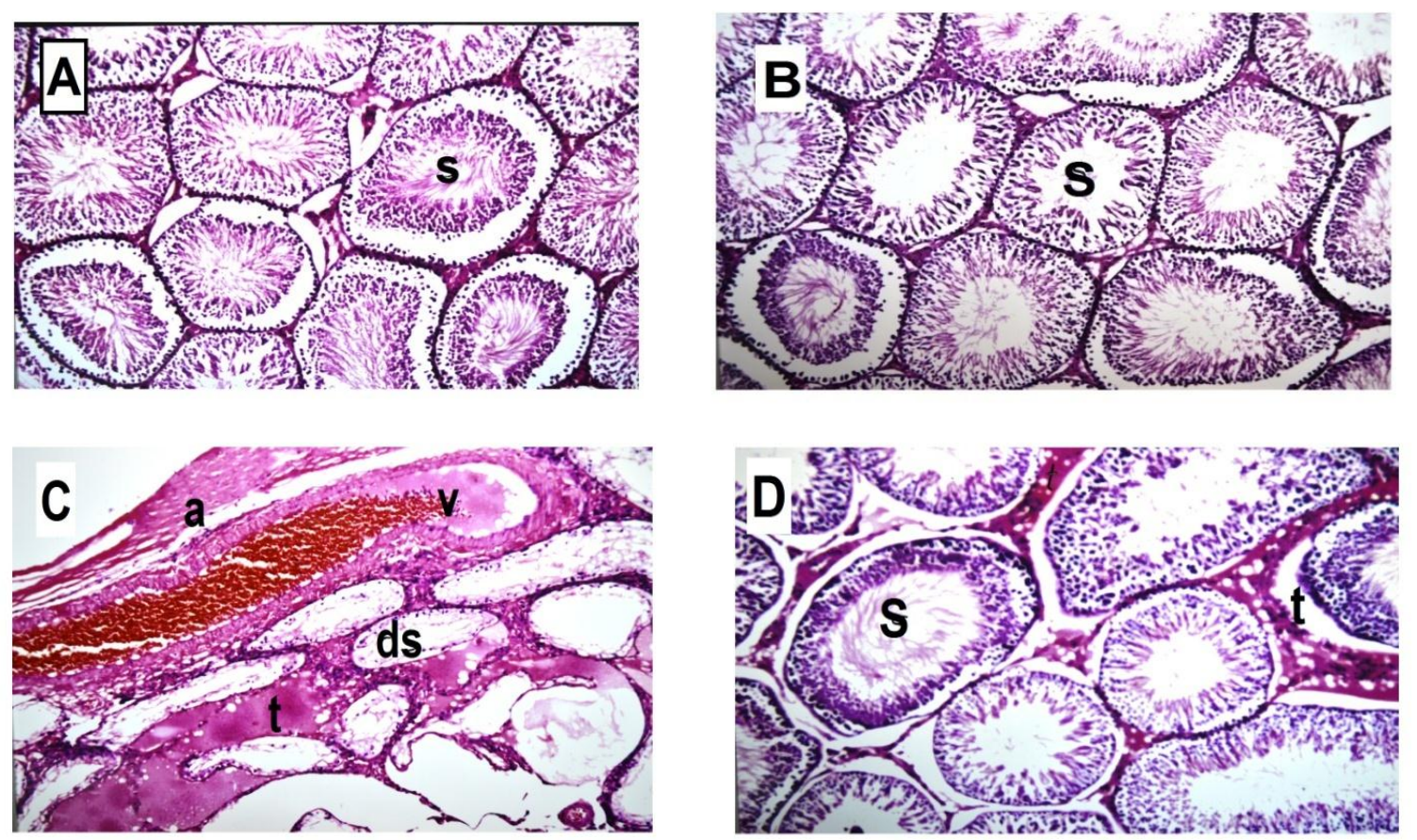

Fig. 5. Effect of L-carnitine on cisplatin-induced alterations in testicular histopathological features in rats. Photomicrographs of testicular sections (A) control and (B) L-CAR groups showing normal intact testicular tissues with mature seminiferous tubules (s) and complete spermatogenic series, (C) CIS treated group displaying marked degeneration in seminiferous tubules (ds) and sever congestion in blood vessels (v) of tunica albuginea (a) with eosinophilic infiltration in the interstitial stroma (t), (D) CIS+L-CAR treated group showing mature active seminiferous tubules ( $\mathrm{s}$ ) with some homogenous eosinophilic material in the interstitial stroma $(\mathrm{t})$ between the seminiferous tubules [H\&E X 40]. CIS, cisplatin; L-CAR, L-carnitine.

Table 4. Testicular histopathological alterations in rats

\begin{tabular}{lccc}
\hline Groups & $\begin{array}{c}\text { Degeneration in } \\
\text { seminiferous } \\
\text { tubules }\end{array}$ & $\begin{array}{c}\text { Congestion in } \\
\text { blood vessels }\end{array}$ & $\begin{array}{c}\text { Edema in } \\
\text { interstitial stromal } \\
\text { tissue }\end{array}$ \\
\hline Control & - & - & - \\
\hline
\end{tabular}




\begin{tabular}{lccc}
\hline L-CAR & - & - & - \\
CIS & ++++ & ++++ & +++ \\
CIS+L-CAR & - & - & + \\
\hline
\end{tabular}

Note: - Nil, + mild damage, ++ moderate damage, +++ severe damage, ++++ very severe. CIS, cisplatin; L-CAR, L-carnitine.

\section{Discussion}

The human testis is a known target organ for injury resulting from exposure to cisplatin. Short- and long-term cisplatin treatments result in germinal epithelial damage, sperm dysfunction and germ cell apoptosis in animals and humans (Cherry et al., 2004; Boekelheide, 2005). Many studies have shown that cisplatin impaired rat testicular structure through inflicting oxidative stress and inducing cell apoptosis (Amin and Hamza, 2006; Amin et al., 2008). Thus, it seems imperative to search for agents that can protect against testicular toxicity whenever cisplatin chemotherapy is employed.

The present study highlights the protective actions of L-carnitine against cisplatininduced testicular toxicity in rats as verified by the restoration of testicular architecture, enhancement of steroidogenesis, preservation of spermatogenesis, modulation of the inflammatory reaction along with suppression of oxidative/nitrosative stress.

In the present study, a significant decrease in body and reproductive organs weights accompanied by marked histopathological alterations in the testicular tissue was observed in cisplatin treated rats, findings that are in agreement with previous work (Azu et al., 2010; Salem et al., 2012; Adejuwon et al., 2015). The reduction in reproductive organs weight is due to marked parenchymal atrophy in germinal cell layers, loss of maturation in the germinal cells and arrested spermatocytes at different stages of division which lead to tubular shrinkage in testicular tissues (Ilbey et al., 2009a; Beytur et al., 2012). Furthermore, the observed reduction in body weight may be due to malnutrition caused by systemic toxic effect of cisplatin (Salem et al., 2012). The histopathological alterations induced by cisplatin, may be explained by the abnormal production of ROS and the imbalance between oxidants and antioxidants in testicular tissue (Boekelheide, 2005; Ilbey et al., 2009b).

Herein, L-carnitine mostly alleviated the reduction in reproductive organs weight induced by cisplatin and caused a significant rescue of testicular function by preserving the intact seminiferous tubular morphology. Ramadan et al. (2002) stated that pretreatment with Lcarnitine reversed most histopathological changes induced by magnetic field. The results of the current study also are in accordance with the study of Gawish et al. (2011) who showed that Lcarnitine improved varicocele-induced degenerative changes in the ipsilateral testis of albino rats.

Moreover, cisplatin-induced reduction in testosterone level was significantly reverted by L-carnitine administration, which is in accordance with preceding investigations (Dehghani et al., 2013; El-Maddawy, 2014; Ahmed et al., 2014; Ghanbarzadeh et al., 2014). This remarkable reduction in the hormonal level might be explained by cisplatin-induced severe damages on leydig and sertoli cells resulting from increased generation of free radicals as one of the possible mechanisms (Tousson et al., 2014). In addition, many reports indicated that cisplatin-induced 
changes in testosterone level may occur through interference with Luteinizing hormone (LH) receptor expression and impairment of the cholesterol mobilization to mitochondrial cytochrome P450 thus interfering with the first steps in testosterone production (Silici et al., 2009; Longo et al., 2011; Beytur et al., 2012).The beneficial effect of L-carnitine on testosterone level may be explained by its anti-oxidative property which prevents oxidative stress induced Leydig cells impairment (Ghanbarzadeh et al., 2014).

Actually, testosterone is essential for the normal spermatogenesis as well as for the maintenance of normal structure of seminiferous tumbles (Sharpe et al., 1992).The spermatogenic impairment in cisplatin-treated rats indicated in the present study isn't only the result of the reduced testosterone level; but it may be also due to the formation of free radical products in the testicular tissues as they exert a detrimental effect on spermatogenesis (Ilbey et al., 2009a; Kaya et al., 2015). The increase in free radical production and the decrease in antioxidant enzymes induced by cisplatin caused a rapid loss of intracellular Adenosine Triphosphate (ATP), leading to loss of sperm motility, axonemal damage and decreased sperm viability (Turk et al., 2008). In addition, the reduction in sperm motility and increased abnormal sperm rate in cisplatin-treated rats may be caused by lipid peroxidation of unsaturated fatty acids in the sperm plasma membrane resulting in loss of its fluidity and function (Atessahin et al., 2006).

Noteworthy, L-carnitine prevented, to a large extent changes in sperm characteristics observed following cisplatin exposure. These results are in agreement with many reports (Yari et al., 2010; Gawish et al., 2011; Ahmed et al., 2014; Yuncu et al., 2015) which indicated that Lcarnitine enhanced sperm count and motility and reduced sperm abnormalities. Such constructive effects may be attributed to the increased hormonal level, decreased apoptotic cell death and suppressed oxidative stress as well as lipid peroxidation (Ghanbarzadeh et al., 2014; Yuncu et al., 2015).

In the current study, cisplatin decreased testicular reduced glutathione (GSH) content as well as superoxide dismutase (SOD), catalase (CAT) and glutathione peroxidase (GPx) activities and elevated malondialdehyde (MDA) level, results that in coherence with previous experimental studies (Amin et al., 2012; Salem et al., 2012; Adejuwon et al., 2015). The decrease in the activities of these enzymes could be explained either with their consumption during the conversion of free radicals into less harmful or harmless metabolites, or due to the direct inhibitory effect of cisplatin on the enzyme activity (Zhao et al., 2014). Due to the high concentration of polyunsaturated fatty acids and low antioxidant capacity, testis is one of the major target organs for oxidative stress and peroxidative damage, a process resulting in reduced sperm viability, motility and thus infertility (Aitken and Curry, 2011; Beytur et al., 2012).

In the present investigation, L-carnitine reduced oxidative stress through attenuation of MDA production and improvement of the antioxidant status in testicular tissues via augmentation of SOD, CAT, GPx and GSH levels. Our results were in harmony with earlier reports showing that L-carnitine attenuated lipid peroxidation and enhanced the antioxidant balance in rat testicular tissues (El-Maddawy, 2014; Ghanbarzadeh et al., 2014; Yuncu et al., 2015). This was probably due to L-carnitine direct antioxidant effects or the enhanced biosynthesis of GSH and the other antioxidant enzymes (Cayir et al., 2009; Ghanbarzadeh et al., 2014). In addition, L-carnitine reduces the availability of lipids for peroxidation by transporting fatty acids into the mitochondria for $\beta$-oxidation and consequently mitigates the production and 
accumulation of lipid peroxidation products (Izgut-Uysal et al., 2003; Dokmeci et al., 2005; Derin et al., 2006).

It is well known that oxidative stress stimulate transcription factors, including NF- $\mathrm{B}$ (Kundu and Surh, 2005), which is a functional link between oxidative damage and inflammation (Hamza et al., 2016). The result of the present study revealed that cisplatin promoted the expression of nuclear factor-kappa $\mathrm{B}(\mathrm{NF}-\kappa \mathrm{B})$ and increased production of tumor necrosis factoralpha (TNF- $\alpha$ ) and nitric oxide (NO). Many studies which in accordance with our result showed that cisplatin-induced oxidative stress upregulated the expression of $\mathrm{NF}-\kappa \mathrm{B}$, which consecutively increased the transcription of TNF- $\alpha$ and inducible nitric oxide synthase (iNOS) resulting in excessive NO production (Sherif et al., 2014; Hamza et al., 2016). Indeed, inflammation is considered as one of the important mechanisms by which cisplatin mediates testicular injury (Ilbey et al., 2009b; Hamza et al., 2016).

The results of the present study, revealed that L-carnitine caused a significant decrease in testicular NF- $\mathrm{KB}$ expression and TNF- $\alpha$ and NO production. These effects are in line with previous studies which reported that L-carnitine can block the activation of NF- $\kappa \mathrm{B}$ signaling pathway (Arafa, 2008; Zambrano et al., 2013). In addition, Ahmed et al. (2014) stated that, Lcarnitine exhibited a powerful down-regulation of mRNA expression of TNF- $\alpha$ and this could be explained in part by its antioxidant activities (Thangasamy et al., 2009) and also by its glucocorticoid-like effect on the expression of pro-inflammatory cytokines (Schetter et al., 2010).

Taken together, it can be concluded that treatment with L-carnitine provided significant and comparable protective effects against cisplatin-induced testicular toxicity in rats. The beneficial actions of this agent may be attributed to its capability to scavenge free radicles, augment antioxidants, and deactivate $\mathrm{NF}-\kappa \mathrm{B}$ signaling pathway. Therefore, we suggest that supplementation with L-carnitine may be beneficial in the clinical treatment of cancer patients with cisplatin while avoiding many of its side effects particularly reproductive system toxicity.

\section{Conflict of interest}

The authors declare that they have no financial or personal conflicts of interest to disclose.

\section{Acknowledgments}

The authors are grateful to Prof. Dr. Adel Bakeir and Prof. Dr. Kawkab A. Ahmed (Department of Histology, Faculty of Veterinary Medicine, Cairo University, Cairo, Egypt) for performing the histopathological and immunohistochemical examinations. 


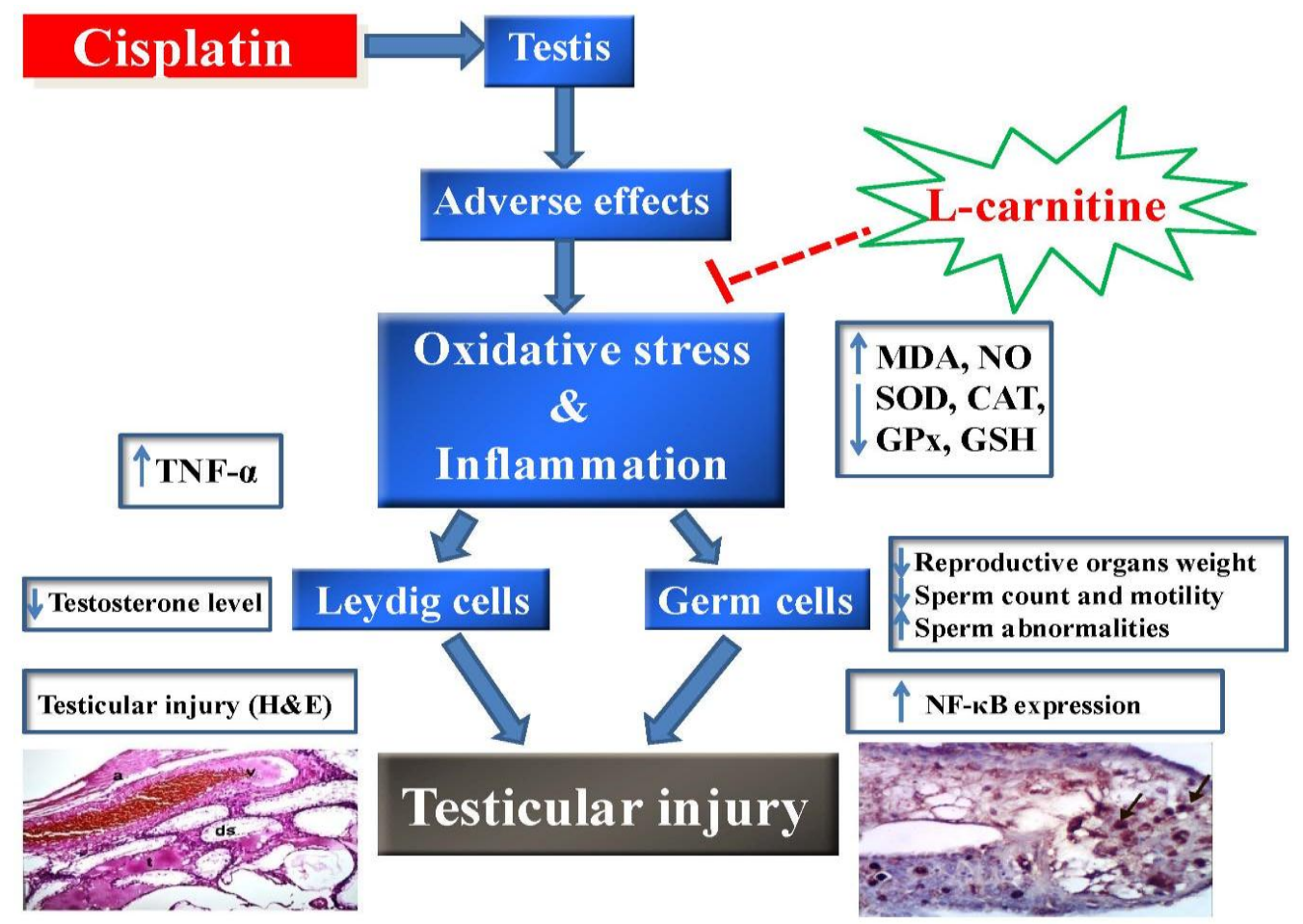

Fig. 6. Diagram illustrating the alleviating action of l-carnitine in cisplatin-induced testicular injury.

\section{EFERENCES}

Abdelrazik, H., Agrawal, A. (2009). L-carnitine and assisted reproduction. Arch Med Sci 5: 43-47.

Adejuwon, S. A., Femi-Akinlosotu, O. M., Omirinde, J. O. (2015). Cisplatin-induced testicular dysfunction and its amelioration by Launaea taraxacifolia leaf extract. Andrologia 47(5): 553-559.

Ahmed, E. A., Omar, H. M., Abd-Elghaffar, S., Ragb, S. M., Nasser, A. Y. (2011). The antioxidant activity of vitamin C, DPPD and L-cysteine against Cisplatin-induced testicular oxidative damage in rats. Food Chem Toxicol 49(5): 1115-1121.

Ahmed, M. M., Ibrahim, Z. S., Alkafafy, M., El-Shazly, S. A. (2014). L-carnitine protects against testicular dysfunction caused by gamma irradiation in mice. Acta Histochem 116(6): 1046-1055.

Aitken, R. J., Curry, B. J. (2011). Redox regulation of human sperm function: from the physiological control of sperm capacitation to the etiology of infertility and DNA damage in the germ line. Antioxid Redox Signal 14(3): 367-381.

Aldemir, M., Okulu, E., Kosemehmetoglu, K., Ener, K., Topal, F., Evirgen, O., Gurleyik, E., Avci, A. (2014). Evaluation of the protective effect of quercetin against cisplatininduced renal and testis tissue damage and sperm parameters in rats. Andrologia 46(10): 1089-1097. 
Aleisa, A. M., Al-Majed, A. A., Al-Yahya, A. A., Al-Rejaie, S. S., Bakheet, S. A., AlShabanah, O. A., Sayed-Ahmed, M. M. (2007). Reversal of cisplatin-induced carnitine deficiency and energy starvation by propionyl-L-carnitine in rat kidney tissues. Clin Exp Pharmacol Physiol 34(12): 1252-1259.

Al-Majed, A. A. (2007). Carnitine deficiency provokes cisplatin-induced hepatotoxicity in rats. Basic Clin Pharmacol Toxicol 100(3): 145-150.

Amin, A., Hamza, A. (2006). Effects of ginger and roselle on cisplatin induced reproductive toxicity in rats. Asian J Androl 8: 607-612.

Amin, A., Hamza, A., Kambal, A., Daoud, S. (2008). Herbal extracts counteract cisplatinmediated cell death in rat testis. Asian J Androl 10: 291-297.

Amin, A., Buratovich, M. A. (2009). New platinum and ruthenium complexes--the latest class of potential chemotherapeutic drugs--a review of recent developments in the field. Mini Rev Med Chem 9(13): 1489-1503.

Amin, A., Abraham, C., Hamza, A. A., Abdalla, Z. A., Al-Shamsi, S. B., Harethi, S. S., Daoud, S. (2012). A standardized extract of Ginkgo biloba neutralizes cisplatinmediated reproductive toxicity in rats. J Biomed Biotechnol 2012: 362049.

Arafa, H. M. (2008). Carnitine deficiency aggravates carboplatin nephropathy through deterioration of energy status, oxidant/anti-oxidant balance, and inflammatory endocoids. Toxicology 254(1-2): 51-60.

Atessahin, A., Sahna, E., Turk, G., Ceribasi, A. O., Yılmaz, S., Yuce, A., Bulmus, O. (2006). Chemoprotective effect of melatonin against cisplatin-induced testicular toxicity in rats. $J$ Pin Res 41(1): 21-27.

Azu, O. O., Duru, F. I. O., Osinubi, A. A., Oremosu, A. A., Noronha, C. C., Elesha, S. O., Okanlawon, A. O. (2010). Histomorphometric effects of Kigelia africana (Bignoniaceae) fruit extract on the testis following short-term treatment with cisplatin in male Sprague-Dawley rats. J Mid East Fertil Soc 15(3): 200-208.

Bearden, H. J., Fluquary, J. (1980). Applied Animal Reproduction. Restore Publishing Co. Inc. Reston, Virginia, USA. pp.158-160.

Beutler, E., Duron, O, Kelly, B. M. (1963). Improved method for the determination of blood glutathione. J Lab Clin Med 61: 882-888.

Beytur, A., Ciftci, O., Oguz, F., Oguzturk, H., Yilmaz, F. (2012). Montelukast attenuates side effects of cisplatin including testicular, spermatological, and hormonal damage in male rats. Cancer Chemother Pharmacol 69(1): 207-213.

Boekelheide, K. (2005). Mechanisms of toxic damage to spermatogenesis. J Natl Cancer Inst Monogr 34: 6-8.

Cayir, K., Karadeniz, A., Yildirim, A., Kalkan, Y., Karakoc, A., Keles, M., Tekin, S. (2009). Protective effect of L-carnitine against cisplatin-induced liver and kidney oxidant injury in rats. Open Med 4(2): 184-191. 
Cetinkaya, A., Bulbuloglu, E., Kantarceken, B., Ciralik, H., Kurutas, E. B., Buyukbese, M. A., Gumusalan, Y. (2006). Effects of L-carnitine on oxidant/antioxidant status in acetic acid-induced colitis. Dig Dis Sci 51(3): 488-494.

Cherry, S. M., Hunt, P. A., Hassold, T. J. (2004). Cisplatin disrupts mammalian spermatogenesis, but does not affect recombination or chromosome segregation. Mutat Res 564: 115-128.

Cocchetto, D. M., Bjornsson, T. D. (1983). Methods for vascular access and collection of body fluids from the laboratory rat. J Pharm Sci 72(5): 465-492.

Dehghani, F., Hassanpour, A., Poost-Pasand, A., Noorafshan, A., Karbalay-Doust, S. (2013). Protective effects of L-carnitine and homogenized testis tissue on the testis and sperm parameters of busulfan-induced infertile male rats. Iran J Reprod Med 11(9): 693-704.

Derin, N., Agac, A., Bayram, Z., Asar, M., Izgut-Uysal, V. N. (2006). Effects of L-carnitine on neutrophil-mediated ischemia-reperfusion injury in rat stomach. Cell Biochem Funct 24(5): 437-442.

Dokmeci, D., Akpolat, M., Aydogdu, N., Doganay, L., Turan, F. N. (2005). L-carnitine inhibits ethanol-induced gastric mucosal injury in rats. Pharmacol Rep 57(4): 481-488.

Dokmeci, D., Inan, M., Basaran, U. N., Yalcin, O., Aydogdu, N., Turan, F. N., Uz, Y. H. (2007). Protective effect of L-carnitine on testicular ischaemia-reperfusion injury in rats. Cell Biochem Funct 25(6): 611-618.

El-Maddawy, Z. K. (2014). Modulation of Gentamicin-induced Testicular and Brain Damage in Rats. Glob J Pharmacol 8(3): 284-293.

Erdincler, D. S., Seven, A., Inci, F., Beger, T., Candan, G. (1997). Lipid peroxidation and antioxidant status in experimental animals: effects of aging and hypercholesterolemic diet. Clin Chim Acta 265(1): 77-84.

Fung, C., Vaughn, D. J. (2011). Complications associated with chemotherapy in testicular cancer management. Nat Rev Urol 8(4): 213-222.

Garcia, C. L., Filippi, S., Mosesso, P., Calvani, M., Nicolai, R., Mosconi, L., Palitti, F. (2006). The protective effect of L-carnitine in peripheral blood human lymphocytes exposed to oxidative agents. Mutagenesis 21(1): 21-27.

Gawish, M. F., Azmy, A. M., El-Haleem, M. R. A. (2011). A histological study of ipsilateral testis after experimentally induced varicocele in albino rats and the role of L-carnitine supplementation. Egy J Histo 34(1), 166-177.

Ghanbarzadeh, S., Garjani, A., Ziaee, M., Khorrami, A. (2014). CoQ10 and L-carnitine attenuate the effect of high LDL and oxidized LDL on spermatogenesis in male rats. Drug Res 64(10): 510-515.

Hamza, A. A., Elwy, H. M., Badawi, A. M. (2016). Fenugreek seed extract attenuates cisplatininduced testicular damage in Wistar rats. Andrologia 48(2): 211-221. 
Ilbey, Y. O., Ozbek, E., Simsek, A., Otunctemur, A., Cekmen, M., Somay, A. (2009a). Potential chemoprotective effect of melatonin in cyclophosphamide- and cisplatininduced testicular damage in rats. Fertil Steril 92(3): 1124-1132.

Ilbey, Y. O., Ozbek, E., Cekmen, M., Simsek, A., Otunctemur, A., Somay, A. (2009b). Protective effect of curcumin in cisplatin-induced oxidative injury in rat testis: mitogen-activated protein kinase and nuclear factor-kappa B signaling pathways. Hum Reprod 24(7): 1717-1725.

Izgut-Uysal, V. N., Agac, A., Derin, N. (2003). Effect of L-carnitine on carrageenan-induced inflammation in aged rats. Gerontology 49(5): 287-292.

Kanter, M., Topcu-Tarladacalisir, Y., Parlar, S. (2010). Antiapoptotic effect of L-carnitine on testicular irradiation in rats. J Mol Histol 41(2-3): 121-128.

Kaya, K., Ciftci, O. , Cetin, A., Dogan, H., Basak, N. (2015). Hesperidin protects testicular and spermatological damages induced by cisplatin in rats. Andrologia 47(7): 793-800.

Kundu, J. K., Surh, Y. J. (2005). Breaking the relay in deregulated cellular signal transduction as a rationale for chemoprevention with anti-inflammatory phytochemicals. Mutat Res 591(1-2): 123-146.

Longo, V., Gervasi, P. G., Lubrano, V. (2011). Cisplatin induced toxicity in rat tissues: the protective effect of Lisosan G. Food Chem Toxicol 49(1): 233-237.

Maines, M. D., Sluss, P. M., Iscan, M. (1990). Cis-Platinum-Mediated Decrease in Serum Testosterone is Associated with Depression of Luteinizing Hormone Receptors and Cytochrome P-450scc in Rat Testis. Endocrinology 126: 2398-2406.

Ng, C. M., Blackman, M. R., Wang, C., Swerdloff, R. S. (2004). The role of carnitine in the male reproductive system. Ann N Y Acad Sci 1033: 177-188.

Okada, F. K., Stumpp, T, Miraglia, S. M. (2009). Carnitine reduces testicular damage in rats treated with etoposide in the prepubertal phase. Cell Tissue Res 337(2): 269-280.

Radwan, R. R., Shaban, E. A., Kenawy, S. A., Salem, H. A. (2012). Protection by low-dose $\gamma$ radiation on doxorubicin-induced nephropathy in rats pretreated with curcumin, green tea, garlic or 1-carnitine. Bulletin of Faculty of Pharmacy, Cairo University 50(2), 133140.

Ramadan, L. A., Abd-Allah, A. R., Aly, H. A., Saad-el-Din, A. A. (2002). Testicular toxicity effects of magnetic field exposure and prophylactic role of coenzyme Q10 and Lcarnitine in mice. Pharmacol Res 46(4): 363-370.

Rezvanfar, M. A., Rezvanfar, M. A., Shahverdi, A. R., Ahmadi, A., Baeeri, M., Mohammadirad, A., Abdollahi, M. (2013). Protection of cisplatin-induced spermatotoxicity, DNA damage and chromatin abnormality by selenium nanoparticles. Toxicol Appl Pharmacol 266(3): 356-365.

Ruiz-Pesini, E., Alvarez, E., Enriquez, J. A., Lopez-Perez, M. J. (2001). Association between seminal plasma carnitine and sperm mitochondrial enzymatic activities. Int $J$ Androl 24(6): 335-340. 
Salama, A. F., Kasem, S. M., Tousson, E., Elsisy, M. K. (2015). Protective role of L-carnitine and vitamin $\mathrm{E}$ on the testis of atherosclerotic rats. Toxicol Ind Health 31(5): 467-474.

Salem, E. A., Salem, N. A., Maarouf, A. M., Serefoglu, E. C., Hellstrom, W. J. (2012). Selenium and lycopene attenuate cisplatin-induced testicular toxicity associated with oxidative stress in Wistar rats. Urology 79(5): 1184 e1181-1186.

Sayed-Ahmed, M. M. (2010). Role of carnitine in cancer chemotherapy-induced multiple organ toxicity. Saudi Pharm J 18(4): 195-206.

Schetter, A. J., Heegaard, N. H., Harris, C. C. (2010). Inflammation and cancer: interweaving microRNA, free radical, cytokine and p53 pathways. Carcinogenesis 31(1): 37-49.

Sharpe, R. M., Maddocks, S., Millar, M., Kerr, J. B., Saunders P. T., McKinnell, C. (1992). Testosterone and spermatogenesis. Identification of stage-specific, androgen-regulated proteins secreted by adult rat seminiferous tubules. J Androl 13(2): 172-184.

Sherif, I. O., Abdel-Aziz, A., Sarhan, O. M. (2014). Cisplatin-induced testicular toxicity in rats: the protective effect of arjunolic acid. J Biochem Mol Toxicol 28(11): 515-521.

Silici, S., Ekmekcioglu, O., Eraslan, G., Demirtas, A. (2009). Antioxidative effect of royal jelly in cisplatin-induced testes damage. Urology 74(3): 545-551.

Thangasamy, T., Jeyakumar, P., Sittadjody, S., Joyee, A. G., Chinnakannu, P. (2009). Lcarnitine mediates protection against DNA damage in lymphocytes of aged rats. Biogerontology 10(2): 163-172.

Topcu-Tarladacalisir, Y. T., Kanter, M., Uzal, M. C. (2009). Role of L-carnitine in the prevention of seminiferous tubules damage induced by gammaradiation: a light and electronmicroscopic study. Arch Toxicol 83(8): 735-746.

Tousson, E., Hafez, E., Masoud, A., Hassan, A. A. (2014). Abrogation by curcumin on testicular toxicity induced by Cisplatin in rats. J Cancer Res Treat 2(3): 64-68.

Turk, G., Atessahin, A., Sonmez, M., Ceribasi, A. O., Yuce, A. (2008). Improvement of cisplatin-induced injuries to sperm quality, the oxidant-antioxidant system, and the histologic structure of the rat testis by ellagic acid. Fertil Steril 89(5 Suppl): 14741481.

Turk, G., Ceribasi, A. O., Sahna, E., Atessahin, A. (2011). Lycopene and ellagic acid prevent testicular apoptosis induced by cisplatin. Phytomedicine 18(5): 356-361.

Yari, A., Asadi, M. H., Bahadoran, H., Dashtnavard, H., Imani, H., Naghii, M. R. (2010). Cadmium toxicity in spermatogenesis and protective effects of L-carnitine in adult male rats. Biol Trace Elem Res 137(2): 216-225.

Yuncu, M., Bukucu, N., Bayat, N., Sencar, L., Tarakcioglu, M. (2015). The effect of vitamin $\mathrm{E}$ and L-carnitine against methotrexate-induced injury in rat testis. Turk J Med Sci 45(3): 517-525.

Zambrano, S., Blanca, A. J., Ruiz-Armenta, M. V., Miguel-Carrasco, J. L., Revilla, E., Santa-Maria, C., Mate, A., Vazquez, C. M. (2013). The renoprotective effect of Lcarnitine in hypertensive rats is mediated by modulation of oxidative stress-related gene expression. Eur J Nutr 52(6): 1649-1659. 
Zare, Z., Mohammadi, M., Eimani, H., Shafaroudi, M. M. (2011). Prevention of di (2ethylhexyl) Phthalate-induced Testicular Disturbance in Mice by Co-administration of L-carnitine. Int J Fertil Steril 5(3): 186-192.

Zhao, Y. M., Gao, L. P., Zhang, H. L., Guo, J. X., Guo, P. P. (2014). Grape seed proanthocyanidin extract prevents DDP-induced testicular toxicity in rats. Food Funct 5(3): 605-611.

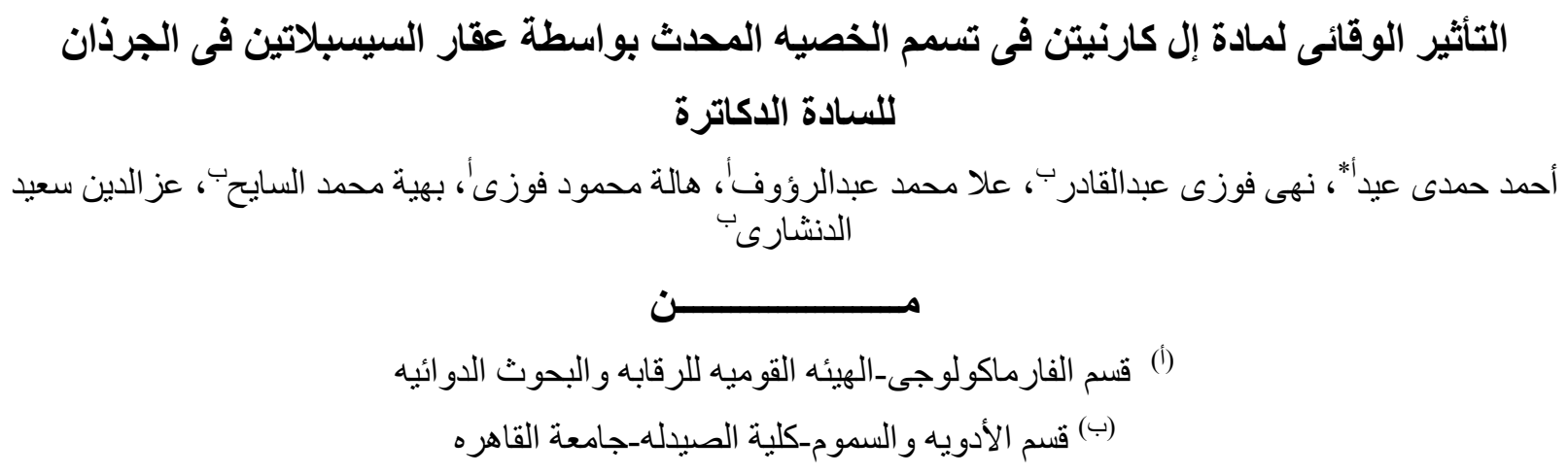

تدمير أنسجة الخصبه يعتبر أحد الثأثير ات الضاره منى تم إستعمال السيسبلاتين فى علاج العديد من أنواع السرطانات.

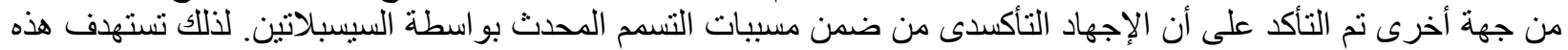

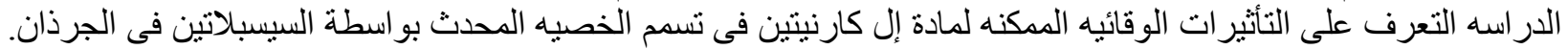

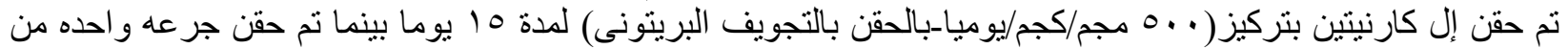

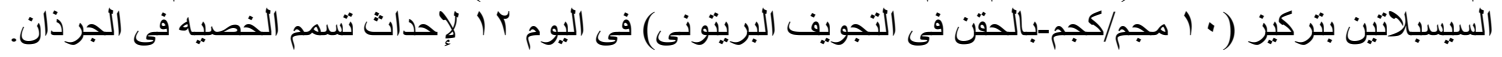

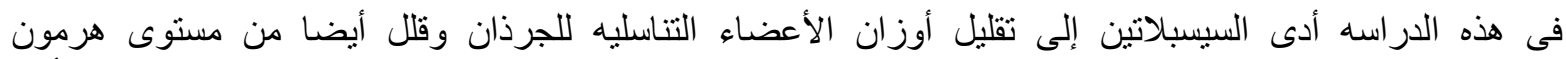

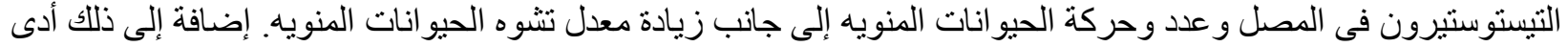

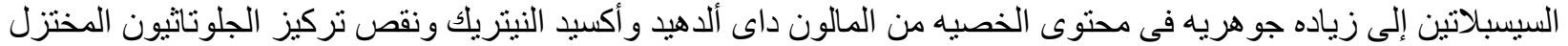

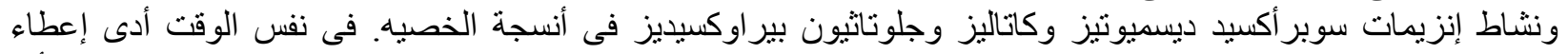

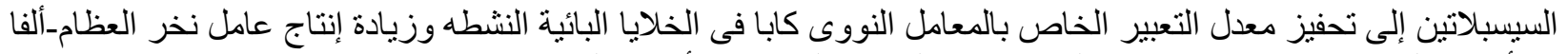

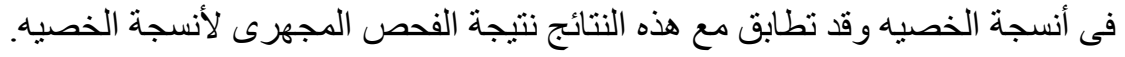

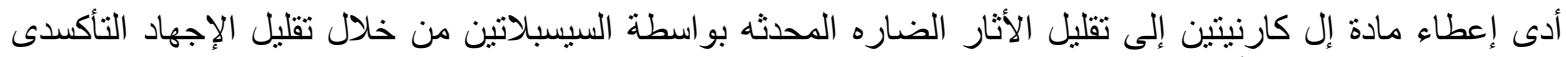

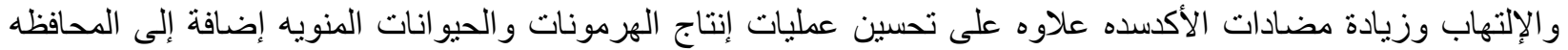

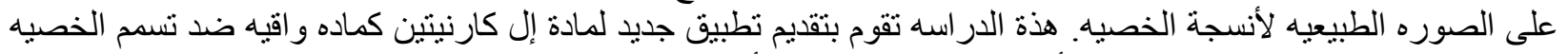
المحدث بو اسطة السيسبلاتين من خلال تأثير اته الر ائعه كمضاد للاكسيده و الإلتهاب. 